\title{
A Study on the English Translation of Public Signs in Downtown Wenzhou
}

\author{
Xingyue Wang, Zhengbing Liu \\ ${ }^{I}$ Oujiang Colllege, Wenzhou University, Wenzhou, Zhejiang 325007, China \\ ${ }^{2}$ Oujiang Colllege, Wenzhou University, Wenzhou, Zhejiang 325007, China
}

\begin{abstract}
As an important export-oriented economic city along the southeast coast of China, Wenzhou plays a pivotal role in the world. The process of internationalization in Wenzhou has accelerated in recent years. While as many as one million Wenzhou people go out to the rest of the world to conduct business activity, travel and further their studies, more and more foreigners come to Wenzhou to do business, study, work and live. Therefore, the importance of English translation of Chinese public signs to foreigners in Wenzhou is selfevident. Through the investigation, the author of this paper has fhas found on the whole, the English translation of public signs in Wenzhou urban areas is good, but there still exist some deficiencies, such as "dead translation", mistranslation and unnecessary omission. The author believes that the English translation of public signs in Wenzhou can be standardized by referring to foreign parallel texts, free translation and creative translation, so as to facilitate foreigners who travel, study, work and live in Wenzhou.
\end{abstract}

Keywords: downtown Wenzhou, English translation of public signs, strategy, liberal translation

\section{INTRODUCTION}

Public signs play a very important role in our life and are widely used. Public signs are ubiquitous and can be seen almost everywhere, such as: transportation facilities, tourist attractions, medical institutions, construction sites and government departments. Public signs are important business cards related to the international image of a city. Their quality directly reflects the cultural connotation and soft cultural construction of a city. Public signs can guide, prompt, warn and force public behaviors in public places. With the deepening of China's reform and opening-up, China is invariably in line with the international community, and the number of international friends who come to China for work exchanges and tourism visits has increased dramatically. English, as an universal language, has been paid more and more attention. With the development of internationalization in recent years, the role of English public signs in international cultural exchanges and cooperation has become increasingly prominent. English public signs play an important role in the cultural exchanges and communication between countries, and they are also an important means of external propaganda. The accuracy and standardization of the English translation of public signs directly reflect the level of civilization and cultural literacy of a country, which plays an active role in establishing a good international image and promoting international cultural exchange. This paper intends to make an empirical study on the English translation of public signs in downtown Wenzhou which is an important exportoriented economic city and puts forward some suggestions for the existing problems.

\section{LANGUAGE CHARCTERISTICS AND USAGES OF ENGLISH PUBLIC SIGNS}

The so-called public signs refer to the written language that the public see in public. They are not only the most common practical language in people's life but a special style that is open to the public and aims to achieve a certain communicative purpose as well. "Public signs can be divided into indicative public signs, suggestive public signs, warning public signs, restrictive public signs, and mandatory public signs." [1]. Generally speaking, public signs can be divided into universal and specialized ones. Universal use refers to the internationally applicable public signs, while the specialized one refers to the publicity, slogans, advertisements which are used by individuals or groups in the conduction of social and commercial activities.

\subsection{Mainly using nouns}

English public signs use a large number of nouns (or gerunds) which can directly demonstrate specific content and convey succinct expressions. For example: no plus noun (or gerund): No Smoking or nouns (gerund) plus past participle: Smoking Strictly Prohibited; the other is noun (gerund) plus adverb: Safety First, or as a central word: Diverted Traffic. 


\section{APPRECIATION OF SOME GOOD ENGLISH TRANSLATION OF THE PUBLIC SIGNS IN DOWNTOWN WENZHOU AND EXAMPLES OF BAD ONES}

Touch; Violators Will be Severely Punished; Valuables in View ; Handle With Care.

\subsection{Using phrases}

The structure of phrases is simple and diverse in combination, which can effectively convey the central meaning of the public signs. For example: Be aware of the Dog; Out of Stock; Sold Out.

\subsection{With the help of acronyms}

Public signs of public facilities or services which are most frequently accessed by the public are identified by acronyms. The advantage is that the central content is highlighted and is expressed in a concise and clear form. For example: VIP Lounge (Very Important People's Lounge); BRT (Bus Rapid Transit); F\&B(Food and Beverage ).

\subsection{The sentence is simple in structure and unique in form}

In order to make sure that the audience can understand the message in a relatively short period of time, the structure of the public signs should avoid being so complicated. At the same time, the English public signs are written in full (or parts that need to be emphasized) capital, or the first letter of the notional words. Punctuation marks are often not used at the end of sentences. For example, GLASS; YOU MIND THE STEP; Caution! Wet Floor! ; School Ahead.

\subsection{Using multipurpose imperative sentences}

Imperative sentences have been widely used in English public signs for the audiences who are often in a hurry. The target audience for the public signs is clear, so imperative sentences in the English public language has a large number of applications, such as: Lower Window For Ventilation; Hold the Hand Rail; Mind Your Head; Please Keep Off The Grass.
Wenzhou, or "Wen" for short, is a famous historic and cultural city with a history of more than 2,000 years. Wenzhou has a rich cultural heritage, outstanding people, and is rich in tourism resources. In recent years, with the development of economy and culture, Wenzhou has gradually become one of the favored destinations for international friends to visit, play, study and work. Bilingualism of public signs is an inevitable trend for Wenzhou to go international. Most of the public signs in downtown Wenzhou are written in both Chinese and English, which play a guiding and warning role that the public signs should have. The correct use of public signs will have a positive effect; on the contrary, the wrong expression will lead to ridiculous or even immeasurable loss. So, what kind of harm do wrong English public signs do? First of all, foreigners do not understand it after reading it, which does not play a positive role in propaganda and prompt at all. Secondly, some sentences and phrases are irregular, which may lead foreigners to getting puzzled and will damage the image of the city. Thirdly, wrong public signs may lead the outsiders' a negative impression on, which will further effect communication and cooperation. There is no doubt that English translation of public signs Wenzhou are, on balance, good, but some have some shortcomings, and some even make people confused.

\subsection{Spelling and grammatical errors}

The English translation of public signs should conform to the norms of English language choice and sentence-making. However, the author has has found that some English translations of public signs in downtown Wenzhou is wrong in spelling, capitalization and lexicon. For example, in a building in Huaxinyuan District in downtown Wenzhou, the public sign "In Case of Fire, Do not in Use Lift", appears so confusing to English readers. The suggested answer could be: Do not use the elevator in case of fire. Similarly, in the English public sign in the Wenzhou Zoo Scenic Area, "Violators will be fine", the word fine should have been in spelt as fined. The correct English translation should be: Violators will be fined. Here fine is used as a verb which means to punish.

\subsection{Literal translation}

"Translation is by no means a simple copy of the source information, but rather a creative imitation of the translator's work in the source language[2]." When translating Chinese public signs into English, we should avoid over-emphasis on each word, no more or less than the exact number, as if it is impossible to express the 
complete meaning without doing so. For example, in "Prohibit Open Fire in Public" for the Chinese public sign" 公共场合禁止明火"in Wenzhou Yintai Department Store, the for"明" is translated into "open fire", "火" is translated into "fire", and"禁止" is translated into "prohibit", which is a typical way of a literal translation. The suggested English translation may be "No Open Flame in Public".

\subsection{Wrong Choice of words}

Languages differ from each other in the division and introduction of concepts. "The most difficult situation in communication is a different understanding of two sentences which convey the same meaning but in different languages." [3] There may be several choices when translating a Chinese word into English. If translators cannot accurately distinguish the nuances between different words, there will be a conceptual dissonance in the English translation. The author has found that the English translation of some public signs in downtown Wenzhou is not satisfactory. For example, in the Wenzhou Zoo, the Chinese "快速通道" is translated into "Express Lane". But according to the Longman Dictionary of Contemporary English[4], "lane" usually refers to the rural road or the "lane" in the road name. Obviously, translating "通道" into "lane" in English is a typical wrong choice of word. The proposed translation may be: Express Passage.

\subsection{Indiscriminating translation}

Translation requires translators to chew the original words. According to $\mathrm{Xu}$ Jun, a contemporary well-known figure in the field of translation in China, if we put translation into the background of human cultural exchange, we can see clearly that translation is not only a simple conversion of text symbols but also involves all aspects of cultural exchange: the cultural value of text accumulation, the cultural soil in which the text is located, the starting culture and objectives involved in the text conversion, the relationship between languages and cultures, etc.[5] However, we have found that some English translation of some public signs in downtown Wenzhou has the suspicion of arbitrary translation. For example, "请随手关灯" in the Central Ryman-Haton Community is translated into "Please Close Lamp". The verb in this sentence is translated into "close" and "灯" is translated into "lamp" , which is ridiculous to English audience. The suggested translation may be: Turn Off Lights When Not In Use.

\subsection{Overloading translation}

In translation, overloading translation (overtranslation) is not recommended unless necessary, especially for the convenience of the target readers. Over-translation is not only a literal asymmetry but also a cultural difference.
Chinese translators may lack enough sensitivity to cultural differences, but for the target readers of the public signs, namely, the recipients of information, the negative cultural feeling is too strong or even intolerable. Some Chinese public signs do not contain substance, which makes no sense after translation. These English translations lack public signs of "marking, instruction, restriction, coercion"[6] or "instructions, services, prohibitions" [7] and other indicative functions. However, we have found that the overloading translation is not uncommon in the English translation for the public signs in downtown Wenzhou. For example, the slogan"所有商品概不讲价" in a clothing store in the 5050 Malls is translated into "All Fixed Prices. No bargain", which is a typical overloading translation. And it is suggested to be translated into "No Bargaining ". " 温馨提示" in a coffee shop near the well-known Wuma Street is translated into English as "a gentle reminder". The word "gentle" is added to the English translation so as to extend emotion. However, the word "gentle" has no substantive publicity effect. This translation may well make English readers wonder whether there is a reminder without "gentle". Obviously, in this English translation, the word "gentle" is unnecessary, and it be discarded.

\subsection{Unauthentic English or Chinglish}

The English translation of public signs should follow the lexical and syntactic norms of English, just like the translation of other styles. However, we have found that in some public toilets in downtown Wenzhou, the public sign "来也勿勿,去也訒勿" is translated into "Come in Hurry, Go in In Hurry" which really makes people laugh. The suggested translation may be "Flush After Use ". On a road in downtown Wenzhou, the sign "限速 5 公里" is translated into" Speed Limit is 5 Kilometer. " The English translation of this sign is totally Chinglish. The suggested translation may be "Speed Limit 5 kilometers". As Qian Zhongshu, a translator master in China said, a good translation should have no traces of translation.

\subsection{Overemphasis on equivalent rhymes}

Translation is not always in a word-to-word activity. Many Chinese public signs emphasize lyricism, emphasizing rhymes. They are very aesthetic and instructive to read aloud. But does the corresponding English translation also need to be that perfect? The answer is No. Wan Zhengfang and others think that mistranslation is mainly due to the fact that translators ignore the differences between Chinese and English in language and culture. The Chinese mode of thinking and aesthetic requirements transplanted into their corresponding English translation, and the English translation is carried out according to the Chinese literal meaning and grammatical structure. Through the investigation, we have also confirmed this view. For example, we have found that on the lawn of Jiushan Park in downtown Wenzhou, the public sign "小草在睡觉, 我们不 
dragons are synonymous with evil. When people use dragons to describe people, it always has a derogatory meaning. Again, bamboo in Chinese culture is considered to have a high moral character, and it is the embodiment of high moral integrity while in the West, there is no bamboo planted. Bamboo is a borrowed word from Chinese. Naturally, there is no extension of the bamboo's arrogance and nobility.

\section{AN ANALYSIS OF THE CAUSES OF ERRORS IN ENGLISH TRANSLATION OF PUBLIC SIGNS IN DOWNTOWN WENZHOU}

There are many reasons for the errors in English translation of public signs in downtown Wenzhou. Some are the result of direct borrowing from Baidu Translation while others are owing to poor editing. Of Course, translators are more responsible for that. When one learns a foreign language, he is inevitably influenced by his mother tongue, so Chinese people may well follow the Chinese habitual wording when they speak and translate Chinese into English, and that is why Chinglish is born.

\subsection{Machine translation}

The quality of the English translation of the public signs is directly related to its translators, who should have subjective initiatives. Translators are supposed to transform the two languages involved in translation. The translation of public signs is not only a text but also a cultural transformation. In fact, both international tourism standard graphic signs and Chinese public information (including tourism) standard graphic signs, which are widely used as special international language signs for international tourism and public information services. Through investigation, we have found that the English translation of some o public signs in downtown Wenzhou is not done by professional translators. As the subject of the translation, "the translator is both the recipient of the original information and the sender of the source information" [8], "and in manipulating the original, transforming the original, adjusting the bilingual language and cultural differences plays a leading role"[9]. Some translations are obviously completed by the machine or poor-quality software translations, while others are literally translated based on the definition of words in dictionaries.

\subsection{Cultural vacancies}

Many Chinese words can not find their equivalents in English, which brings great difficulties to translation. "On the micro-level, some linguistic phenomena are untranslatable and cannot be completely equivalent even if translated reluctantly". [10] For example, in Chinese culture, dragon is the king of the marine creatures, and Chinese people have always been proud to call themselves the descendants of the dragon. But in Western culture,

\subsection{Lacking thorough understanding of the meaning of English vocabulary}

When Chinese English learners inquire about the meaning of an English word, they are more accustomed to inputting words directly into translation software or electronic dictionary to seek the corresponding Chinese meaning displayed. In fact, the Chinese meanings for many English words do not convey show their English counterparts' full meaning, especially the hidden meaning (such as emotion and derogatory meaning). The Chinese public slogan "残疾 人专用" is translated into "special for the deformed"[11]. However, the English interpretation of the word "deformed" is "have a shape that is not normal because it has grown wrongly", which corresponds to the Chinese meaning "畸形的" and has negative connotations. For people with disabilities who read this public slogan may well feel offended and disrespected. Therefore, when translating public slogans into English, the translator should choose as many neutral words as possible. In fact, there are far more examples of nonstandard English translation and writings of public signs in downtown Wenzhou. Only by fully understanding the cultural differences between the East and the West, making clear the true meaning of words and grasping the scale of translation can the translator make his or her English translation appropriate and authentic.

\section{STRATEGIES FOR ENGLISH TRANSLATION OF CHINESE PUBLIC SIGNS}

\subsection{Referring to foreign parallel texts}

Translators should learn to draw inferences from one instance. Nowadays, it is not difficult to find ready-made English public signs for Chinese public signs. Many scholars have done a lot of research on the translation of public signs, which can be collected and sorted out by translators. It is wise to directly use the established expressions or slightly make changes in the translation. Referring to foreign parallel texts is a preferred method for the translation of public signs, which is simple and can generally guarantee the accuracy of the translation. However, it should be noted that there is no objection to the choice of original English expressions for those customary English public signs. But at the same time, while copying, 
we should also pay much attention to the unity of usage habits and styles, and pay attention to the variety of English variants as well. You can also ask native English speakers for help to get a better understanding of the feelings and needs of the readers.

\subsection{English public signs use fewer verbs}

English public signs and Chinese public signs are extremely different. The former use fewer verbs, but use more nominal words so as to achieve simplicity, because public signs usually do not have too many layouts. Instead, they are sometimes with pictures, and too many words can hardly achieve the effect of warning and reminding. On the other hand, using nouns appears to be more formal.

\subsection{Flexible use of a few common words}

In English public signs, there are several common words, such as caution, danger, and No. Caution expresses the meaning of a warning to remind people of something; danger is to inform people of potential dangers, and No is telling visitors "do not do something" followed by a noun. Such as No Smoking; No Parking.

\subsection{Referring to the pictures of various public signs in English-speaking countries}

In the process of translating Chinese public signs into English, we can search relevant English expressions in English-speaking countries, click on the pictures, find the relevant signs, and translate them authentically and correctly from the above mentioned.

\subsection{Making sure the translation grammatically correct}

A lot of English public signs, at first sight, may seem to be correct, but taking a closer look at the grammar of the sentence, we may they are full of mistakes. In order to translate public signs well, the translator must ensure his or her translation is grammatically correct and authentic.

\subsection{Sticking to accuracy and precision}

Translation of public signs is not only the simple translation of vocabulary but also the accurate transmission of the connotation of public signs. Therefore, the translation of public signs should be accurate and intuitive so that people who see it will not have ambiguity or even cannot understand it. The space of public signs is very limited. Once the public signs are not accurate, the audience's actions will often be inconsistent with the expectations of the public signs, resulting in serious consequences.
Therefore, its translation requires brevity. According to the principle of conciseness, some function words, such as copula and articles, can be omitted in translation, which will not affect the overall expression effect.

\section{CONCLUSION}

The appropriate and accurate expression of English public signs in public places may provide many foreigners who come to China with homecoming experience, thus leaving a good impression on China, and even give the country's English-speaking people a sense of cultural pride. Chinese and English languages represent different cultures. Public signs fall into the applied styles and English translation of Chinese public signs must be reader-oriented, in line with the English expression habits and ways of thinking, so that foreign friends can understand them at a glance, and truly achieve the purpose of foreign exchange and publicity. Public signs universally exist. Chinese public signs can basically find the same function in English. Translators should try their best to apply the existing customary statements in English and convey the original information with the expressions acceptable to the target English readers so that the readers do not sense too much language strangeness in the public signs. For this reason, the translation of public signs should try to adopt the borrowing doctrine.

One can also turn to people who really understand English for help in terms of translating and checking English translation of Chinese public signs. The translation and expression of public signs not only affect the food, accommodation, traveling, and purchase of international friends in China, but also affect China's international image. We must pay enough attention to them. Mastering the characteristics and rules of English public signs is the responsibility of each public publisher and translator. We all need to understand their functional significance, and truly improve the accuracy and standardization of the English translation of public signs in Chinese. Those mistranslated and untranslated versions of public signs have not only damaged the civilized image of we Chinese people but also affected the international image of the country.

\section{ACKNOWLEDGMENT}

This work is supported by the 2019 Student Research Project at Wenzhou University Oujiang College.

\section{REFERENCES}

[1] Lv Hefa, On Functional Features and ChineseEnglish Translation of the Expressions on Public Signs, Terminology Standardization and Information Technology, 2005(2). (In Chinese.) 
[2] Jin Shengxi, Lin Zhengjun, The Conceptional Blending Mechanism in the Construction of A Translator's Subjectivity, Foreign Languages and Their Teaching, 2016(1). (In Chinese.)

[3] Wang Dechun, An Introduction to Linguistics, Nanjing: Jiangsu Education Press, 1990. (In Chinese.)

[4] Longman Dictionary of Contemporary English, Beijing: Beijing Language Teaching and Research Press, 2004. (In Chinese.)

[5] Xu Jun, Intersubjectivity and Horizon Fusion in Translation, Foreign Language Teaching and Research, 2003(4). (In Chinese.)

[6] Dai Zongxian, Lv Hefa, On Chinese-English Translation of Public Signs, Chinese Translators Journal, 2005(6). (In Chinese.)

[7] Fan Guifang, Intertextuality Perspective in the Translation of Public Signs, Chinese Science and Technology Translators Journal, 2010(4) (In Chinese.)

[8] Liao Qiyi, Contemporary Translation Studies in UK. Wuhan: Hubei Education Press, 2001. (In Chinese.)

[9] Fang Mengzhi, A Dictionary of Translation Studies, Shanghai: Shanghai Foreign Language Education Press, 2007. (In Chinese.)

[10] Wu Dongmei, Cultural Differences in Lexical Levels in English-Chinese Translation. Jiangxi social sciences, 2006(2). (In Chinese.)

[11] Macmillan English Dictionary, Bejing: Beijing Language Teaching and Research Press, 2007. 